\title{
Specific tonotopic organizations of different areas of the human auditory cortex revealed by simultaneous magnetic and electric recordings
}

\author{
C. Pantev * , O. Bertrand a , C. Eulitz, C. Verkindt ${ }^{\text {a }}$, S. Hampson, G. Schuierer ${ }^{\text {b }}$, T. Elbert \\ Center of Biomagnetism, Institute of Experimental Audiology University of Münster, Kardinai-von-Galen-Ring 10, D-48129 Münster, Germany \\ ${ }^{a}$ Brain Signals and Processes Laboratory, INSERM Unité 280, F-69003 Lyon, France \\ ${ }^{\mathrm{b}}$ Institute of Clinical Radiology, University of Münster, D-48129 Münster, Germany
}

\begin{abstract}
This paper presents data concerning auditory evoked responses in the middle latency range (wave Pam/Pa) and slow latency range (wave $\mathrm{N} 1 \mathrm{~m} / \mathrm{N} 1$ ) recorded from 12 subjects. It is the first group study to report multi-channel data of both MEG and EEG recordings from the human auditory cortex. The experimental procedure involved potential and current density topographical brain mapping as well as magnetic and electric source analysis. Responses were compared for the following 3 stimulus frequencies: 500 , 1000 and $4000 \mathrm{~Hz}$. It was found that two areas of the auditory cortex showed mirrored tonotopic organization; one area, the source of $\mathrm{N} 1 \mathrm{~m} / \mathrm{N} 1 \mathrm{wave}$, exhibited higher frequencies at progressively deeper locations, while the second area, the source of the Pam/Pa wave, exhibited higher frequencies at progressively more superficial locations. The Pa tonotopic map was located in the primary auditory cortex anterior to the $\mathrm{N} 1 \mathrm{~m} / \mathrm{N} 1$ mirror map. It is likely that $\mathrm{N} 1 \mathrm{~m} / \mathrm{N} 1$ results from activation of secondary auditory areas. The location of the Pa map in A1, and its N1 mirror image in secondary auditory areas is in agreement with observations from animal studies.
\end{abstract}

Keywords: Middle latency auditory evoked potential; Middle latency auditory magnetic field; Evoked potential; Evoked magnetic field; Tonotopic organization; EEG; MEG; MRI; Auditory cortex

\section{Introduction}

An auditory stimulus triggers a series of time-locked transient evoked responses along the auditory pathway, the earliest of which are the brain-stem responses occurring within the first $10 \mathrm{msec}$. During the following time segment a series of overlapping cortical activations can be recorded: the oscillatory gamma-band response, the middle latency components, and the slow auditory responses (with latencies longer than $80 \mathrm{msec}$ ). If the auditory stimulus continues for several seconds, a stimulus-locked DC shift (sustained response) can also be observed.

The middle latency response (MLR) has received con-

\footnotetext{
* Corresponding author. Fax: +49 (251) 83-6882; E-mail: pantev @uni-muenster.de.
}

siderably less attention than the slow auditory response. This is due to the smaller amplitude (low signal-to-noise ratio) of the MLR and the difficulty in separating neural from myogenic generators (Bickford et al., 1964; Streletz et al., 1977). To record such short waves, a high degree of neural synchronization is required and, hence, acoustic clicks, Gaussian pulses and short tone bursts usually serve as stimuli. Middle latency potentials appear from 10 to 60 msec after stimulus onset. Six different waves have been reported: N0 (latency of about $8 \mathrm{msec}$ ), P0 (about 12 $\mathrm{msec}$ ), $\mathrm{Na}$ (about $18 \mathrm{msec}$ ), $\mathrm{Pa}$ (about $30 \mathrm{msec}$ ), $\mathrm{Nb}$ (about $40 \mathrm{msec}$ ) and P1 (about $50 \mathrm{msec}$ ); the negative/positive complex $\mathrm{Na} / \mathrm{Pa}$ is consistently observed in normal subjects, whereas all other waves are variable in latency and morphology, as well as in frequency of occurrence across subjects (Mendel and Goldstein, 1971; Picton et al., 1974; Streletz et al., 1977; Özdamar and Kraus, 1983). 
The possible origin of the middle latency responses is still a subject of debate. Epidural recordings and direct cortical recordings of auditory responses to monaural stimulation (Celesia, 1976; Lee et al., 1984; Liegeois-Chauvel et al., 1987, 1991) indicate generators located in Heschl's gyri of both temporal lobes active in the latency range of 12-37 msec. Given latency variations for the different species, similar activation was found in the primary auditory cortex of cats (Buchwald et al., 1981) and monkeys (Arezzo et al., 1975; Steinschneider et al., 1992).

From the scalp distribution of middle latency auditory evoked potentials it has been inferred that generators lie symmetrically within both temporal lobes (Cohen, 1982; Wood and Wolpaw, 1982). A source model for both $\mathrm{Na}$ and $\mathrm{Pa}$, proposed by Scherg and Von Cramon (1986) suggests two dipolar sources in each temporal lobe whose activation partially overlaps in time, the major current dipole being tangentially oriented and the other radially. In contrast, Deiber et al. (1988) have attributed Na to deeper subcortical sources on the basis of a sequential mapping study. With respect to the generators of $\mathrm{Pa}$, the results of Deiber et al. (1988) were in line with those of Scherg and Von Cramon (1986), favoring the view that this middle latency wave can be related mainly to the simultaneous activation of both supratemporal auditory cortices. The $\mathrm{Na}$ and $\mathrm{Pa}$ results obtained from patients with unilateral temporal lobe lesions are controversial. Whereas Kileny et al. (1987) have shown that $\mathrm{Pa}$ can be reduced while $\mathrm{Na}$ remains intact when measured over the damaged hemisphere, Scherg and Von Cramon (1990) have demonstrated that unilateral lesions of the auditory cortex or of the acoustic radiation reduce or even eliminate tangential $\mathrm{Na}$ and $\mathrm{Pa}$ dipole moments in the lesioned hemisphere. In addition, the results of studies investigating the functional relations of the middle latency responses and their sources to important parameters of the auditory stimulus as well as to vigilance or sleep are incomplete and contradictory (Erwin and Buchwald, 1986b; Deiber et al., 1989). The work of Littman et al. (1992) in guinea pigs suggests that two MLR morphologies should be distinguished: one recorded over the temporal cortex and the other over the posterior midline. Evidence from normal subjects and patients with temporal lobe lesions (Kraus, 1992) confirms that similar components may be involved in the human MLR. These components may correspond to the two dipolar sources of Scherg and Von Cramon (1986). In Kraus' model, it is proposed that the MLR generating system receives contributions from both primary and non-primary auditory cortex. The mid-line components, which develop early, are rate resistant, sensitive to attention and not affected by lesions, while the temporally generated MLR, which becomes larger for monaural stimulations, is rate sensitive but not affected by attentional variables.

The few neuromagnetic studies investigating middle latency responses (Pelizzone et al., 1987; Reite et al., 1988; Scherg et al., 1989; Pantev et al., 1993) are as yet insufficient to enable a clear determination of the underlying neural sources of the middle latency fields. The magnetic counterpart of the $\mathrm{Na}$ wave ( $\mathrm{Nam}$ ) cannot be observed in most of the subjects. The major magnetic component observed by Pelizzone et al. (1987) and Pantev et al. (1993) was the $\mathrm{Pa}$ wave with a latency about $30 \mathrm{msec}$ after the stimulus onset. Compared to the major component of the slow auditory evoked field - N1m (latency about 100 msec) - the source of Pam was found to be located more anterior and more medial than the equivalent source of $\mathrm{N} 1 \mathrm{~m}$, suggesting that various deflections in the auditory evoked field reflect activities in different areas of the auditory cortex.

Tonotopy is a general principle of functional organization of the auditory system. It arises in the cochlea and is maintained throughout the central auditory pathway, including the primary auditory cortex. It has been demonstrated in animals (Merzenich and Brugge, 1973; Merzenich et al., 1975, 1976; Schreiner, 1991) and in humans (Elberling et al., 1982; Romani et al., 1982; Lauter et al., 1985; Pantev et al., 1988, 1989; Yamamoto et al., 1988; Bertrand et al., 1991; Tiitinen et al., 1993). The depth of the source of the N1m wave reflects the tonotopic organization in the human auditory cortex: the higher the stimulus frequency, the deeper the location of the current dipole accounting for the N1m. Moreover, in most subjects, the depth of this $\mathrm{N} 1 \mathrm{~m}$ dipole increases linearly with the logarithm of the stimulus frequency. Frequency-dependent changes of dipole parameters were also obtained in electric potential and current density studies (Bertrand et al., 1988, 1991). These authors found that in electric recordings the tonotopic cortical organization is reflected most clearly in the dipole orientation, which changes significantly as a function of the stimulus frequency. This frequency-dependent dipole orientation, which can be more accurately estimated from electric than from magnetic recordings (Stok et al., 1987), agrees with the frequency-dependent depth changes of the N1m equivalent source.

The auditory map of the primate is structured as a mosaic with several areas responsive to stimulation of a given frequency interspersed at several points among the representations of other frequencies. Furthermore, attention to natural stimulation can modify the tonotopic organization of the primary auditory area (Recanzone et al., 1993). The equivalent current dipole model for analysis of MEG data, which results in the derivation of a single focus of brain activity, can provide only a rough approximation of this intricate pattern.

Frequency-dependent information concerning middle latency response parameters is limited. In the study of Farlan et al. (1977), stimulus frequency did not have a significant effect on the middle latency potentials, whereas Thornton et al. (1977), Scherg and Volk (1983), and Kraus and McGee (1988) reported $\mathrm{Pa}$ amplitudes at the vertex to be larger for low frequency stimuli than for high frequency stimuli. A tonotopic representation of the source for the 
middle latency responses has not been reported, with the exception of inconclusive evidence in the single case study of Scherg et al. (1989).

The intracellular currents in the pyramidal cells of the auditory cortex flow essentially tangentially to the scalp and hence produce distinct MEG signals, while biological "noise" arising from radial or deep sources remains largely suppressed. For this reason, the MEG is an ideal tool for the investigation of tangentially oriented current dipoles. The EEG results from extracellular volume currents and therefore can provide a further source of information about the same physiological event.

Multi-channel MEG and multi-channel EEG measurements were combined in the present study to investigate the sources of the middle latency responses as well as the possible tonotopic organization of those sources. For the first time, the functional organization of the source of the major middle latency wave $\mathrm{Pa}$ / Pam was uncovered in a group study and compared with the known tonotopic organization of the $\mathrm{N} 1 / \mathrm{N} 1 \mathrm{~m}$ source of the slow auditory evoked response.

\section{Methods}

\subsection{Subjects}

Seven female and 5 male subjects between the ages of 20 and 33 years (mean 24.7 years) with no history of otological or neurological disorders and normal audiological status (air conduction and bone conduction thresholds no more than $10 \mathrm{~dB}$ hearing level in the range from 250 to $8000 \mathrm{~Hz}$ ) participated in this study. All subjects were right-handed as determined with a modified handedness questionnaire of Annett (1967). Informed consent was obtained from each subject after the nature of the study was fully explained. The subjects were paid for their participation.

\subsection{Stimulation}

Short tone bursts of $50 \mathrm{msec}$ duration $(3 \mathrm{msec}$ rise and decay time, cosine function) and $60 \mathrm{~dB} \mathrm{nHL}$ (normative hearing level) were presented to the subject's right ear (contralateral to the MEG-investigated hemisphere) with an interstimulus interval randomized between 600 and 800 msec. The carrier frequencies were 500, 1000 and 4000 $\mathrm{Hz}$. Blocks of 500 stimuli for each frequency were presented 3 times in random order; thus, each frequency appeared a total of 1500 times. The magnetically silent delivery of auditory stimuli to the test subject required a special delivery system with speakers (compressor driver type) outside the magnetically shielded room and echo-free tone transmission through $6.3 \mathrm{~m}$ of plastic tubing $(16 \mathrm{~mm}$ inner diameter) to a silicon earpiece. This system can deliver a $0-100 \mathrm{~dB}$ nHL stimulus intensity with almost linear frequency characteristics in the range between 200 and $4000 \mathrm{~Hz}$ (deviations less than $\pm 4 \mathrm{~dB}$ ). During stimulus presentation the subjects were asked to keep their eyes open, and to stay awake and fixate their gaze onto small complex pictures.

\subsection{Data acquisition}

\subsection{1. $M E G$ recordings}

Recordings were carried out in a magnetically shielded room using a 37-channel biomagnetometer (Biomagnetic Technologies). The detection coils of the biomagnetometer are arranged in a circular concave array with a diameter of $144 \mathrm{~mm}$, and a spherical radius of $122 \mathrm{~mm}$. The axes of the detection coils are normal to the surface of the sensor array. The distance between the centers of two adjacent coils is $22 \mathrm{~mm}$; each coil itself measures $20 \mathrm{~mm}$ in diameter. The sensors are configurated as first-order axial gradiometers with a baseline of $50 \mathrm{~mm}$. The spectral density of the intrinsic noise of each channel is between 5 and $7 \mathrm{fT} / \sqrt{\mathrm{Hz}}$ in the frequency range above $1 \mathrm{~Hz}$. The subjects lay in a right lateral position with their head, neck and upper part of the body supported by a specially fabricated vacuum cushion. A sensor position indicator system determined the spatial locations of the sensors relative to the head and indicated if head movements occurred during the recordings. The sensor array was centered over a point about $1.5 \mathrm{~cm}$ superior to the position $\mathrm{T} 3$ of the $10-20$ system for electrode placement and was positioned as near as possible to the subject's head. Using a bandwidth from 1 to $100 \mathrm{~Hz}$ and a sampling rate of $520.8 \mathrm{~Hz}$ (16-bit ADC), stimulus-related epochs of 300 msec (including $100 \mathrm{msec}$ prestimulus baselines) were recorded and stored for further analysis. The slope was 6 $\mathrm{dB} /$ oct for the high-pass filter and $60 \mathrm{~dB} /$ oct for the low-pass filter.

\subsubsection{EEG recordings}

Simultaneous with the magnetic recordings, electric potentials were recorded from $26 \mathrm{Ag}-\mathrm{AgCl}$ electrodes referenced to the nose (Fig. 1c). Electrode impedance for all electrodes was below $5 \mathrm{k} \Omega$. After preamplification the electric signals underwent the same type of processing by amplifiers, filters and A/D converters, as described for the magnetic signals.

\subsection{Data analysis}

For each stimulus frequency 3 blocks of 500 stimulusrelated epochs were available for averaging. Epochs contaminated by muscle or eye blink artifacts (signal variations of more than $3 \mathrm{pT}$ in the MEG, $100 \mu \mathrm{V}$ in the EEG) were automatically rejected from the averaging procedure. Since the wave forms of the averaged responses of the 3 blocks reproduced excellently (test/retest/retest), the 
grand average of the responses across blocks was used for further evaluation. The baseline was corrected for each channel according to the mean value of the signal during the $100 \mathrm{msec}$ prior to the stimulus. For the analysis of the slow fields and potentials, responses were filtered using a low-pass of $20 \mathrm{~Hz}$ (second-order zero-phase shift Butterworth filter, $12 \mathrm{~dB} /$ oct).

\subsubsection{Mapping}

Scalp potentials and magnetic field maps were generated on a color graphic terminal using a spherical spline interpolation algorithm (Perrin et al., 1989). For scalp potential mapping, the electrodes were considered to be located on a spherical surface following the 10-20 system strategy, with T3, Fpz, T4 and $\mathrm{Oz}$ being equispaced on the equatorial circle and $\mathrm{Cz}$ located at the upper pole. The spline interpolation was performed on the sphere, and 2D maps were constructed by computing the radial projection from a viewpoint ( $\mathrm{T} 3$ for left lateral views) that respects the length of the meridian arcs (Perrin et al., 1990). In addition, scalp current density (SCD) maps were estimated by computing the second derivative (Laplacian) of the interpolated potential distribution. SCDs have the property of being reference-free, and of having sharper peaks and valleys than scalp potential distributions. This facilitates interpretation in cases in which there are multiple overlapping sources. For magnetic field mapping, the 37 sensors were considered as located on a sphere with a radius of $122 \mathrm{~mm}$.

\subsubsection{Source analysis}

The source analyses of the simultaneously recorded multi-channel EEG and MEG data were performed separately for the electric potentials and magnetic fields and the estimated underlying sources were then compared.

$E E G$. To identify the neural sources underlying the middle latency and slow auditory evoked potentials, equivalent current dipoles in a 3-concentric sphere head model were used. Conductivity values and radii of the 3 layers, mimicking the brain, the skull and the scalp, were chosen according to Rush and Driscoll (1969). The electrode locations were computed on the sphere using the same model as for the mapping procedure. While it seems sufficient with magnetic data to search for a single moving dipole in the recorded hemisphere, it is mandatory with electric data to look for at least two dipoles, one in each hemisphere, corresponding to the simultaneous activity of both auditory cortices. We have thus used a time-varying modeling strategy based on dipoles having a stationary location and orientation and with their magnitude changing with time (Scherg, 1990).

In contrast to the MEG data, models have been fitted to the grand average response across subjects during short time periods around the peaks of the different waves ( $\mathrm{Pa}$ and N1). During this time segment the experimental data may be fairly well explained by two equivalent current dipoles. Indeed, averaging the electric responses of all the subjects tends to blur the contribution of certain underlying sources, but at the same time improves the signal-to-noise ratio of the recorded data, especially for the middle latency waves; this makes it possible to exhibit the most prominent features characterizing the frequency dependence of the major neural generators. A relative residual error (RRE) was computed as a quadratic difference between experimental and model data (both of them average-referenced) normalized by the quadratic energy of the signal in the studied time period and was minimized by the fitting procedure (the same measure was also used for the MEG data). Equivalent current dipoles were found by an iterative algorithm starting from arbitrary initial values of the dipole parameters. To detect possible local minima of the quadratic criterion and to check the uniqueness of the solution, 100 minimization procedures were performed with randomized initial values for each component and each frequency condition.

$M E G$. Source analyses based on a single moving equivalent current dipole (ECD) model in a spherical volume conductor (Sarvas, 1987) were applied to both magnetic field distributions studied: bandwidths $1-100 \mathrm{~Hz}$ and $1-20$ $\mathrm{Hz}$. The size of the sphere was determined by a fit to the scalp in the area of measurement. It was in this area that the shape of the scalp was digitized with the sensor position indicator. The center and the radius of the best fitting sphere were determined using a least squares fit algorithm. The relative angulation of the pick-up coils and the influence of the volume currents were taken into account for the source analysis. Source locations, their confidence volumes and the dipole moment were estimated for each sampling point in a head-based coordinate system. The origin of this coordinate system was set at the midpoint of the medio-lateral axis (y-axis) which joined the center points of the entrance to the acoustic meatuses of the left and the right ears (positive towards the left ear). The posterior-anterior axis ( $\mathrm{x}$-axis) was oriented from the origin to the nasion (positive towards the nasion) and the inferior-superior axis ( $\mathrm{z}$-axis) was perpendicular to the $\mathrm{x}-\mathrm{y}$ plane (positive towards the vertex).

The estimated source locations ( $x, y, z$ coordinates) of the different waves: Nam, Pam, Nbm, P1m (middle latency fields, cf. Fig. 1b) and N1m and P2m (slow fields, cf. Fig. $1 b$ ) were determined by means of the following manipulations. For each wave the time interval (hereafter termed "evaluation interval") containing the field maximum and minimum, the RMS maximum, and the RRE minimum were determined. The spatial ECD coordinates $(x, y, z)$ for each wave of the middle latency field were assigned to the corresponding averaged values of 5 adjacent sampling points $(9.6 \mathrm{msec})$ around the center of the obtained evaluation interval. For the slow auditory evoked fields this number of sampling points was seven $(13.4 \mathrm{msec})$. However, only those $x, y$ and $z$ values were included in the 
average which further fulfilled the following conditions based on statistical and anatomical considerations: (a) RRE below $10 \%$ for the middle latency and below $5 \%$ for the slow auditory evoked fields; (b) distance of the ECD to the midsagittal plane more than $2 \mathrm{~cm}$; (c) inferior-superior value greater than $1 \mathrm{~cm}$; (d) confidence volume of the source location smaller than $0.3 \mathrm{~cm}^{3}$.

\subsubsection{Statistics}

EEG parameters. The middle latency and the slow wave peaks were detected in each subject and for each frequency condition as the extreme RMS value. At those selected latencies, the amplitude of the response at each electrode was measured. To compare statistically the topography of magnetic recordings electrical recordings
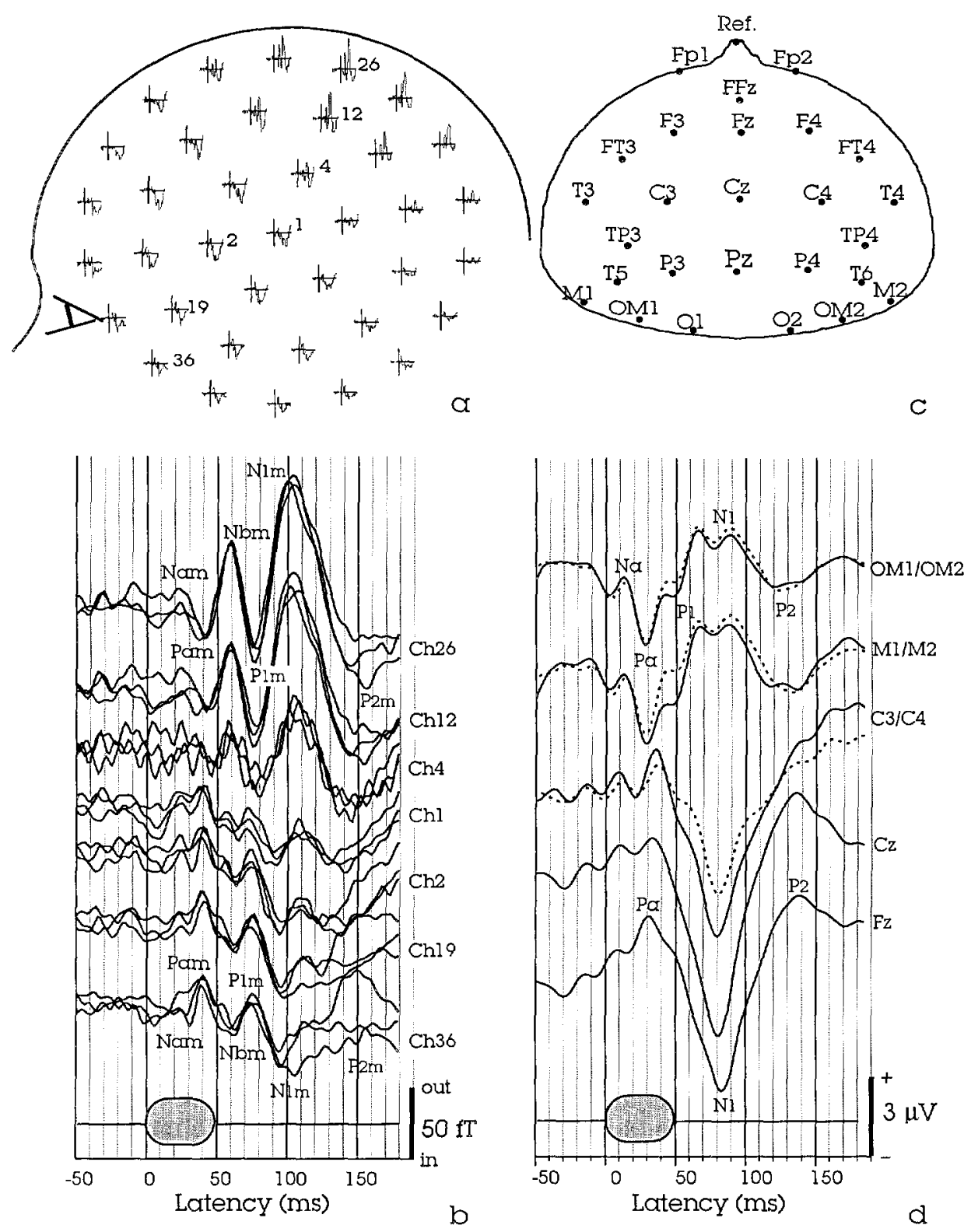

Fig. 1. a: set of 37 averaged wave forms $(\mathrm{N}=1500)$ of $300 \mathrm{msec}$ length $(100 \mathrm{msec}$ prestinulus time), obtained in the passband $1-100 \mathrm{~Hz}$ from the left hemisphere of one subject in response to a $50 \mathrm{msec}, 1000 \mathrm{~Hz}$ tone burst. The wave forms are projected not exactly in scale onto a sketch of the head. The vertical bars represent the stimulus onset. b: enlarged presentation of the magnetic wave forms from the region marked by the channel numbers in a, containing the minimum and the maximum of the field. The 3 blocks of averaged responses (test/retest/retest), consisting of 500 stimulus-related epochs each, are supperimposed in order to demonstrate the reproducibility of the successive regordings. The middle latency wave peaks, Nam, Pam, Nbm, P1m, and the slow wave peaks, $\mathrm{N} 1 \mathrm{~m}$ and $\mathrm{P} 2 \mathrm{~m}$, are indicated. c: scheme of the electrode sites used for recording the auditory evoked potentials. d: corresponding electric wave forms, obtained in the passband $1-100 \mathrm{~Hz}$ to the $1000 \mathrm{~Hz}$ tone burst, selected from the electrode positions as marked on the right. Evoked potentials at selected right and left symmetrical electrodes are superimposed. The middle latency wave peaks, $\mathrm{Na}, \mathrm{Pa}, \mathrm{P} 1$, and the slow wave peaks, $\mathrm{N} 1$ and $\mathbf{P} 2$, are indicated. 

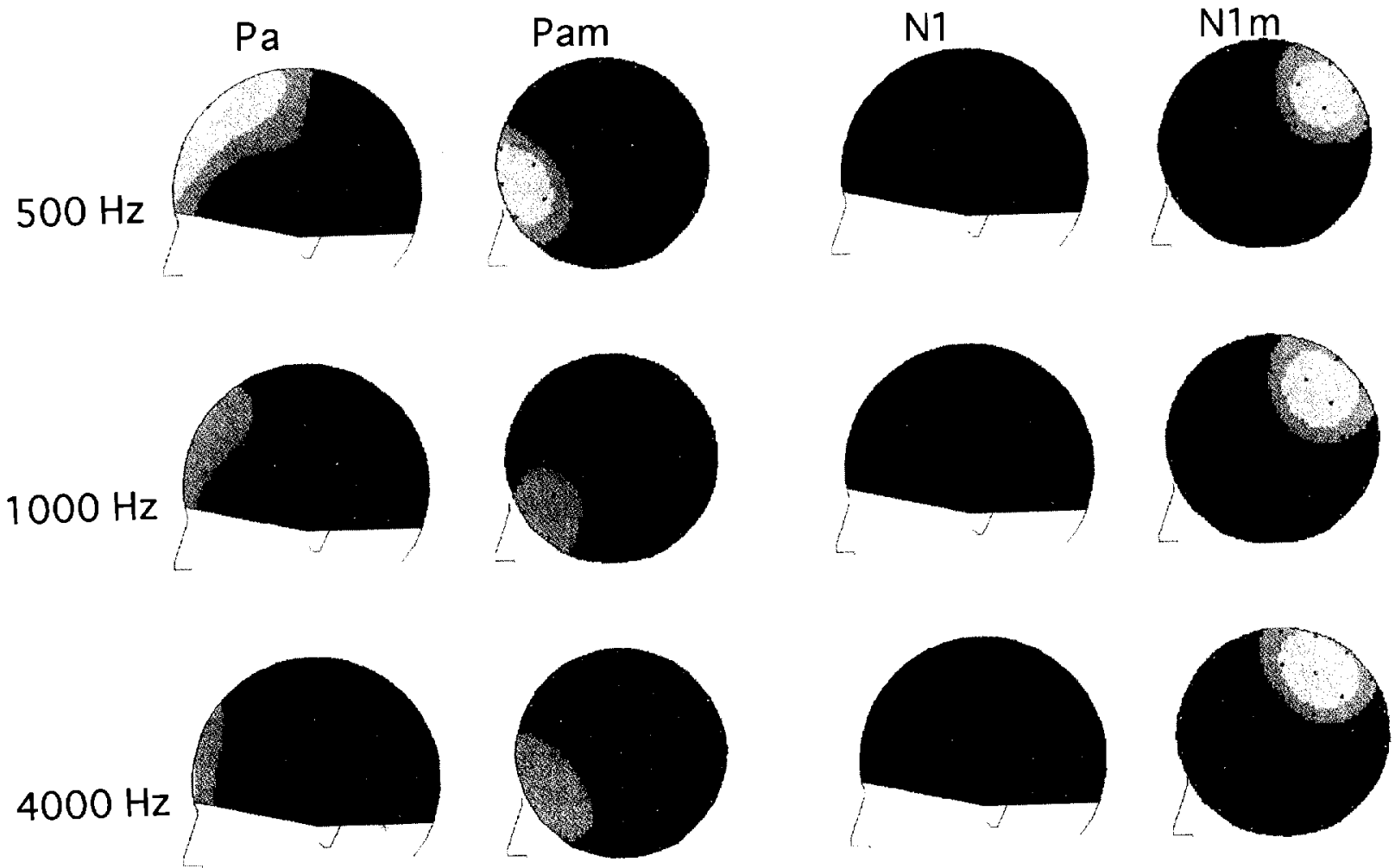

(2)
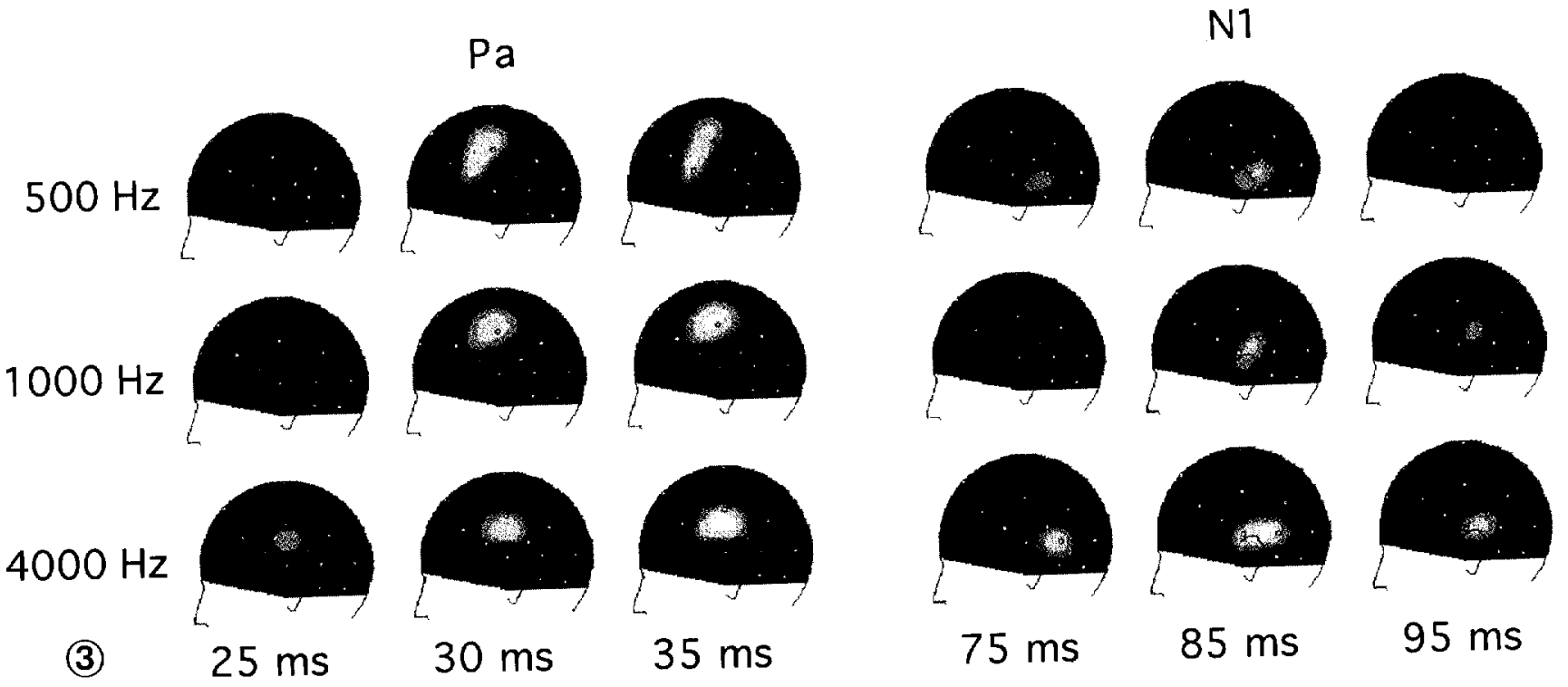

$95 \mathrm{~ms}$

Fig. 2. Electric and magnetic maps of auditory evoked cortical activity. EEG and MEG maps of subject w20 have been selected at the latency of the maximum RMS value for both electric and magnetic evoked responses (waves Pa/Pam, $30 \mathrm{msec}$ and N1/N1m, $89 \mathrm{msec}$ ). Yellow color represents positive potential and outgoing magnetic field, red color negative potential and ingoing magnetic field, dark blue zero values. Amplitude scales are: Pa $\pm 2.2 \mathrm{mV}, \mathrm{N} 1 \pm 5.4 \mathrm{mV}$, Pam $\pm 25 \mathrm{fT}, \mathrm{N} 1 \mathrm{~m} \pm 90 \mathrm{fT}$. Potential maps are viewed from the left side only to facilitate comparison with the magnetic field maps.

Fig. 3. Sequences of scalp current density maps around $\mathrm{Pa}$ and N1 peaks for the 3 stimulus frequencies (estimated from the grand average over the 8 subjects considered for the electrical data analysis). Color scale: yellow/green for positive currents, red for negative currents, dark blue for zero values. Amplitude scales: $\mathrm{Pa} \pm 0.46 \mathrm{~mA} / \mathrm{m}^{3}, \mathrm{~N} 1 \pm 0.91 \mathrm{~mA} / \mathrm{m}^{3}$. 
the components between frequencies, a particular subset of electrodes was considered, including postero-lateral and coronal electrodes (O1, M1, T5, T3, C3, Fz, C4, T4, T6, $\mathrm{M} 2$, and $\mathrm{O} 2$ ). This subset largely covers the lateral polarity reversals of the potential distribution. Furthermore, in each case, amplitudes were normalized by the amplitude measured on the $\mathrm{Fz}$ electrode to eliminate global amplitude differences between frequency conditions, thereby focusing the analysis exclusively on differences in the voltage pattern across electrode locations (McCarthy and Wood, 1985). Two-way analyses of variance (ANOVA) were performed with electrode and stimulus frequency as factors. While this ANOVA showed significant effects, 1-way ANOVAs were performed on the responses of each electrode separately. For the sake of clarity only results of the later analysis will be presented. The possibility that peak latencies were dependent on stimulus frequency was also tested by means of the 1-way ANOVA.

$M E G$ parameters. The posterior-anterior, medial-lateral, inferior-superior ECD locations, the RMS amplitude, the RRE of the fit, and the dipole moment were used as dependent variables in the statistical analysis of the MEG results for effects of stimulus frequency $(500,1000$, and $4000 \mathrm{~Hz}$ ) and wave (Pam and N1m) of the auditory evoked field. Frequency and wave were used as repeated measures factors in a 2-way ANOVA. Where appropriate, probabilities were adjusted by the Greenhouse-Geisser correction. Post-hoc comparisons were carried out using the Scheffé test. Peak latency differences between electric and magnetic data were investigated by means of paired $t$ tests. A dependency of peak latencies on the stimulus frequency was tested by means of 1-way ANOVA.

\subsection{MRI overlays}

In order to establish the plausibility of the calculated sources, all estimated source locations were superimposed onto the corresponding individual MRIs. The 3D MR data sets were generated with the $1.5 \mathrm{~T}$ clinical MR imaging system (Magnetom SP, Siemens). A 3D T1-weighted gradient echo sequence (TR $10 \mathrm{msec}$, TE $4 \mathrm{msec}$, TI 300 msec, 128 partitions, TA 6:48 min), which allow for a good contrast between gray and white cerebral matter, was used. Using a recording matrix of $256 \times 256$ pixels, a field of view of $250 \mathrm{~mm}$, and thickness of the sagittally oriented 3D slab of $192 \mathrm{~mm}$, this MP-RAGE sequence provides a plane resolution of $1 \times 1 \mathrm{~mm}$ in the sagittal and $1 \times 1.5$ $\mathrm{mm}$ in the reconstructed axial and coronal slices. The subject's head was aligned and supported in the MR tomograph using an individually prepared biting piece and a vacuum cushion, which stabilized the head and prevented movement artifacts. The same anatomical landmarks used to create the MEG head-based 3D coordinate system (nasion and entrance of the auditory meatus of the left and right ear) were visualized in the MR images by affixing to these points capsules with an inner diameter and a height of $3 \mathrm{~mm}$ that were filled with Gd-DTPA solution (Schering AG, Berlin), whose short $\mathrm{T} 1$ relaxation time provides a high signal in T1-weighted images. The common MEG and MRI anatomical landmarks allowed easy transformation of the head-based Cartesian coordinate system used by the MEG source analysis to the MRI. The MEG source locations were converted into pixels and slice values using the MRI transformation matrix and inserted onto the corresponding MRIs.

\section{Results}

\subsection{Wave forms, field and potential maps}

Fig. 1a and $b$ show the data set with the most pronounced middle latency magnetic field to $1000 \mathrm{~Hz}$ short tone burst stimulation. In Fig. 1a, the field traces are projected onto a sketch of the head in terms of their approximate relative location to one another. The well-defined dipolar structure of the field distribution is easily recognized in this figure.

Fig. 1b shows an enlargement of the details of the wave forms from the region marked by numbers in Fig. 1a; the magnetic activity of the supratemporal cortex located along the line connecting the minimum and the maximum of the field is represented. In order to demonstrate that the averaged responses of the 3 recorded blocks of 500 stimulusrelated epochs reproduced excellently, these test/retest/ retest responses were superimposed in Fig. 1c for the respective recording channels. In this data set the middle latency waves $\mathrm{Nam}, \mathrm{Pam}, \mathrm{Nbm}$ and $\mathrm{P} 1 \mathrm{~m}$ and the slow waves $\mathrm{N} 1 \mathrm{~m}$ and $\mathrm{P} 2 \mathrm{~m}$ are clearly discernible. For each subject and for each frequency, however, only the Pam and $\mathrm{N} 1 \mathrm{~m}$ were consistently present, whereas Nam was discernible for all stimulus frequencies in only 2 subjects, $\mathrm{Nbm}$ in 1 subject and $\mathrm{P} 1 \mathrm{~m}$ in 3 out of the 12 subjects. The calculated mean peak latency of Pam (positive wave peak anterior, negative posterior) was $28.4 \mathrm{msec}$ with a standard error of the mean (S.E.M.) of $0.5 \mathrm{msec}$. The N1m peak (positive posterior, negative anterior) had a mean peak latency of 87.8 , S.E.M. $1.8 \mathrm{msec}$.

Fig. 1c shows the 26 electrode sites used for recording the corresponding electric evoked responses (electrodes $\mathrm{Fp} 1$ and $\mathrm{Fp} 2$ were not considered for the analysis as those locations are particularly sensitive to small eye movements and electrodermal artifacts). Fig. 1d illustrates the corresponding electric responses to $1000 \mathrm{~Hz}$ stimulation. In this case, instead of superimposition of individual blocks, the evoked potentials at selected left and right symmetrical electrodes were superimposed. Several components can be clearly detected here as well: Pa (mean extrema latency $30.7 \mathrm{msec}$, S.E.M. $0.9 \mathrm{msec}$ ) with a positive maximum on fronto-central electrodes and a polarity reversal on postero-lateral electrodes and N1 (mean extrema latency 
$89.0 \mathrm{msec}$, S.E.M. $1.6 \mathrm{msec}$ ) with a negative maximum on fronto-central electrodes and a polarity reversal on postero-lateral electrodes.

Similar to the magnetic recordings, the waves $\mathrm{Na}$ (around $15 \mathrm{msec}$ ), $\mathrm{Nb}$ (around $40 \mathrm{msec}$ ), P1 (around 50 $\mathrm{msec}$ ) and P2 (around $150 \mathrm{msec}$ ) were not clearly distinguishable in all subjects or in all conditions and were thus not considered for further analysis. A significant peak latency difference was found between electric $\mathrm{Pa}$ and magnetic Pam waves (2.3 msec mean delay for $\mathrm{Pa}$, paired $t$ test, $P<0.05$ ), whereas no significant latency difference was found between $\mathrm{N} 1$ and N1m. No frequency dependencies were found for the latencies of $\mathrm{Pam} / \mathrm{Pa}$ and $\mathrm{N} 1 \mathrm{~m} / \mathrm{N} 1$.

Fig, 2 shows scalp potential and magnetic field maps for 3 different stimulus frequencies of one of the subjects investigated. On potential maps, a clear polarity reversal is observed across a line approximately delineating the Sylvian fissure for both $\mathrm{Pa}$ and N1. Pa maps exhibit a positivity more frontally located than the $\mathrm{N} 1$ negativity and a negativity which spreads more across the occipital area. The Pa positivity follows a frontal shift with increasing frequency accompanied by an increase of the posterior negativity. Similarly, the N1 negativity is shifted slightly frontally with an increase of lateral positivity with increasing stimulus frequency. The same type of change in scalp topography with increasing stimulus frequency was observed on the right hemiscalp. This typical topography (with some variability) was found in all subjects and also appears in the grand averaged response distributions.

On magnetic maps, a clear dipolar pattern was found for both Pam and $\mathrm{N} 1 \mathrm{~m}$ waves with a polarity reversal according to the upward (Pam) and downward (N1m) orientation of the underlying neural generators. The changes of the Pam field distribution with increasing stimulus frequency are less pronounced than in the $\mathrm{N} 1 \mathrm{~m}$ distribution, where the positive and negative extremum field values become more distant from each other with increasing frequency. For N1m, the negative and positive extrema are rotated counterclockwise with higher frequency. The zero field isocontours are more anterior for Pam than for $\mathrm{N} 1 \mathrm{~m}$. Visual inspection of the maps indicates that the general orientation of the underlying neural generators is in agreement with electric and magnetic distributions.

The data from 4 of the 12 subjects (e04, h04, h10, h13) were excluded from all further analysis of electrical data because of the high level of residual noise.

Fig. 3 shows sequences of SCD maps around Pa and N1 peaks for the 3 stimulus frequencies. Clear and sharp sink/source patterns are visible on those maps for both waves, reflecting major neural activity in the supratemporal cortex. A closer visual inspection of the sink/source locations indicates a slightly more anterior and inferior current density reversal for the $\mathrm{Pa}$ than for the N1 wave. The Pa lateral sink (red) peaks below electrode T3, while the N1 lateral source (yellow) peaks between electrodes T3, T5 and TP3. For the N1 SCD maps, the lateral source has a larger amplitude for the highest frequency. Similarly, the Pa SCD maps show a lateral sink of slightly larger amplitudes for the highest frequency.

A 1-way ANOVA performed on normalized amplitudes indicates a significant frequency effect (on $\mathrm{O} 1, \mathrm{~T} 5, \mathrm{C} 4$ and $\mathrm{O} 2$ electrodes $F(2,12)>3.9, P<0.05)$ for $\mathrm{Pa}$, and (on T5, T3, C3, C4 and T4 electrodes $F(2,12)>4.6, P<$ $0.05)$ for $\mathrm{N} 1$.

\subsection{Source localization results}

Dipole modeling of the AEP was performed for each frequency on the inter-subject grand average response (more than 10,000 stimulus-related epochs) from 25 to 35 msec for the $\mathrm{Pa}$ and from 75 to $100 \mathrm{msec}$ for the N1. After randomization of the initial dipole parameters, a unique inverse solution was found for each frequency and for each component with two stationary dipoles, one in each hemisphere. The mean RRE across latencies ranges from 1.2 to $1.8 \%$ for $\mathrm{Pa}$ and from 1.7 to $2.0 \%$ for $\mathrm{N} 1$, according to the stimulus frequency. The extremum magnitude of the dipole moments is always higher in the left hemisphere (contralateral to the stimulation) than in the right hemisphere (mean left/right dipole moment ratio is 2.5 for $\mathrm{Pa}$, and 1.4 for N1).

Projections of the dipole positions (filled circles) and of the dipole vector extremities (open squares) are drawn on the top and back views of the spherical head (Fig. 4). For the 3 frequencies represented, dipole moments were normalized to emphasize differences in dipole orientation only. For the $\mathrm{Pa}$ component, the dipoles were oriented frontally and were tilted inward with increasing stimulus frequency. For the N1 component, the dipoles were oriented vertically and the changes with increasing frequency corresponded to a tilt of the dipoles toward more radial orientations. The dipole positions relative to the different stimulus frequencies were found to be close to each other. Comparing the dipole location differences between $\mathrm{Pa}$ and $\mathrm{N} 1$ waves across stimulus frequencies, the positions of the $\mathrm{Pa}$ dipoles were found to be an average of $1 \mathrm{~cm}$ more anterior than the positions of the $\mathrm{N} 1$ dipoles.

The source analysis of the magnetic data provided consistent results for both the Pam and the N1m. Characterized by posterior-anterior, medial-lateral and inferior-superior coordinates; the RMS field value, the RRE, as well as the dipole moment of each subject, the calculated source locations were averaged across subjects for all different stimulus frequencies. The means obtained in this fashion with their standard errors of the mean are illustrated in Fig. 5. Filled squares represent the Pam values; filled circles represent the $\mathrm{N} 1 \mathrm{~m}$ values. The $\mathrm{N} 1 \mathrm{~m}-\mathrm{RRE}$ of subject w18 was higher than $5 \%$ and therefore his N1m source locations were excluded from further evaluation. The low mean values of the RRE indicate that in all subjects the 


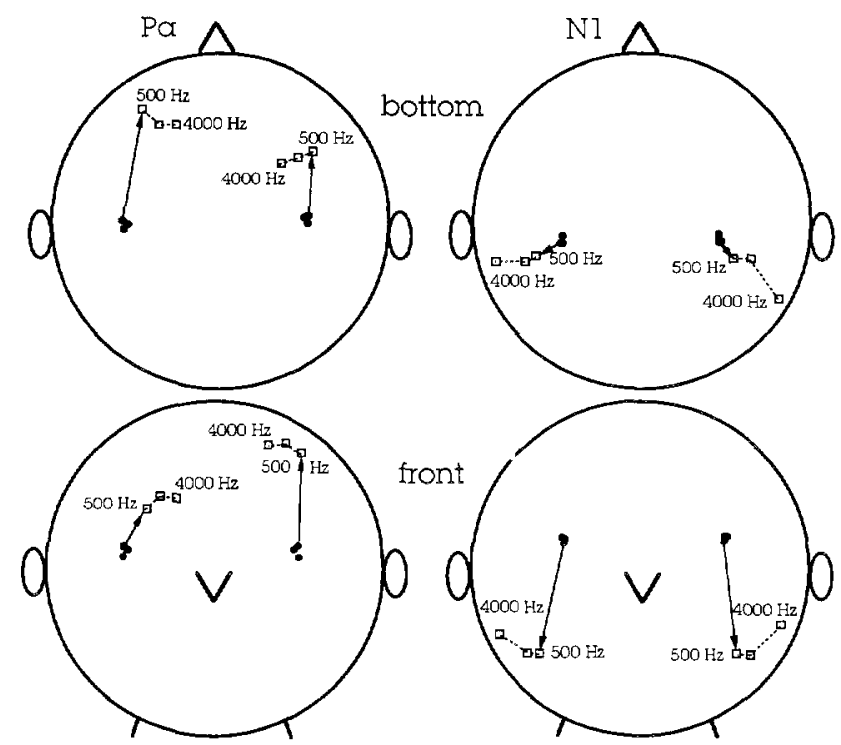

Fig. 4. Bottom and front projections of the stationary equivalent current dipoles found from the electrical potentials in a spherical head model, around $\mathrm{Pa}(25-35 \mathrm{msec})$ and $\mathrm{N} 1(75-100 \mathrm{msec})$. The dipole positions (filled circles) and the dipole vector extremities (open squares) are drawn for the 3 stimulus frequencies (connected by dashed lines). The dipole moments are normalized and for the sake of clarity only the dipole vectors for $500 \mathrm{~Hz}$ tone bursts are presented by arrows.

ECD model used explains most of the field variance. The fit to the model was systematically somewhat better for $\mathrm{N} 1 \mathrm{~m}$ than for Pam (main effect of wave: $F(1,9)=5.9$, $P<0.05)$. The mean RMS field values of $\mathrm{N} 1 \mathrm{~m}$ were significantly larger than those of Pam for all stimulus frequencies (main effect of wave: $F(1,9)=39.1, P<$ $0.001)$. Furthermore, a main effect of frequency $(F(2$,
18) $=8.2, P<0.01)$ was found. Post-hoc Scheffé testing revealed that the main effect of frequency was caused by the RMS difference between 1000 and $4000 \mathrm{~Hz}(P<0.01)$. Similarly, the dipole moment produces main effects of wave $(F(1,9)=11.06, P<0.01)$ and frequency $(F(2$, $18)=6.0, P<0.05$ ). Again, the effect of frequency was due to dipole moment differences between 1000 and 4000 $\mathrm{H}_{z}(P<0.05)$. The source location of Pam was found to be a mean of approximately $5 \mathrm{~mm}$ more anterior than the source of $\mathrm{N} 1 \mathrm{~m}$ (main effect of wave: $F(1,9)=8.1$, $P<0.05$ ). Moreover, the Pam source location was about 5 $\mathrm{mm}$ more superior (main effect of wave: $F(1,9)=27.7$, $P<0.001)$. The most intriguing source localization result, however, was the reverse change of the depth of Pam and $\mathrm{N} 1 \mathrm{~m}$ equivalent current dipoles with increasing the stimulus frequency. Whereas the $\mathrm{N} 1 \mathrm{~m}$ source moves from more lateral to more medial cortical areas with increasing stimulus frequency, the Pam source has an opposite behavior, showing a mirror-image tonotopic representation, changing from more medial to more lateral areas with increasing the stimulus frequency. These results are corroborated by the 2-way ANOVA, indicating a significant interaction of wave $\times$ frequency $(F(2,18)=37.1, P<0.0001)$. Posthoc Scheffé comparisons for this interaction showed significant differences in depth of the $500 \mathrm{~Hz}$-Pam-source from the Pam sources evoked by the $1000(P<0.05)$ and $4000 \mathrm{~Hz}(P<0.001)$ tones. For the N1m a significant difference of depth was found for the sources evoked by the $500 \mathrm{~Hz}$ and the $4000 \mathrm{~Hz}$ tones $(P<0.01)$. The following differences were found between Pam and N1m locations: Pam $-500 \mathrm{~Hz}$ from N1m-500 Hz $(P<0.001)$; and Pam-500 Hz from N1m-1000 Hz $(P<0.01)$; Pam-1000 $\mathrm{Hz}$ from the $\mathrm{N} 1 \mathrm{~m}-500 \mathrm{~Hz}(P<0.05)$; and finally, the
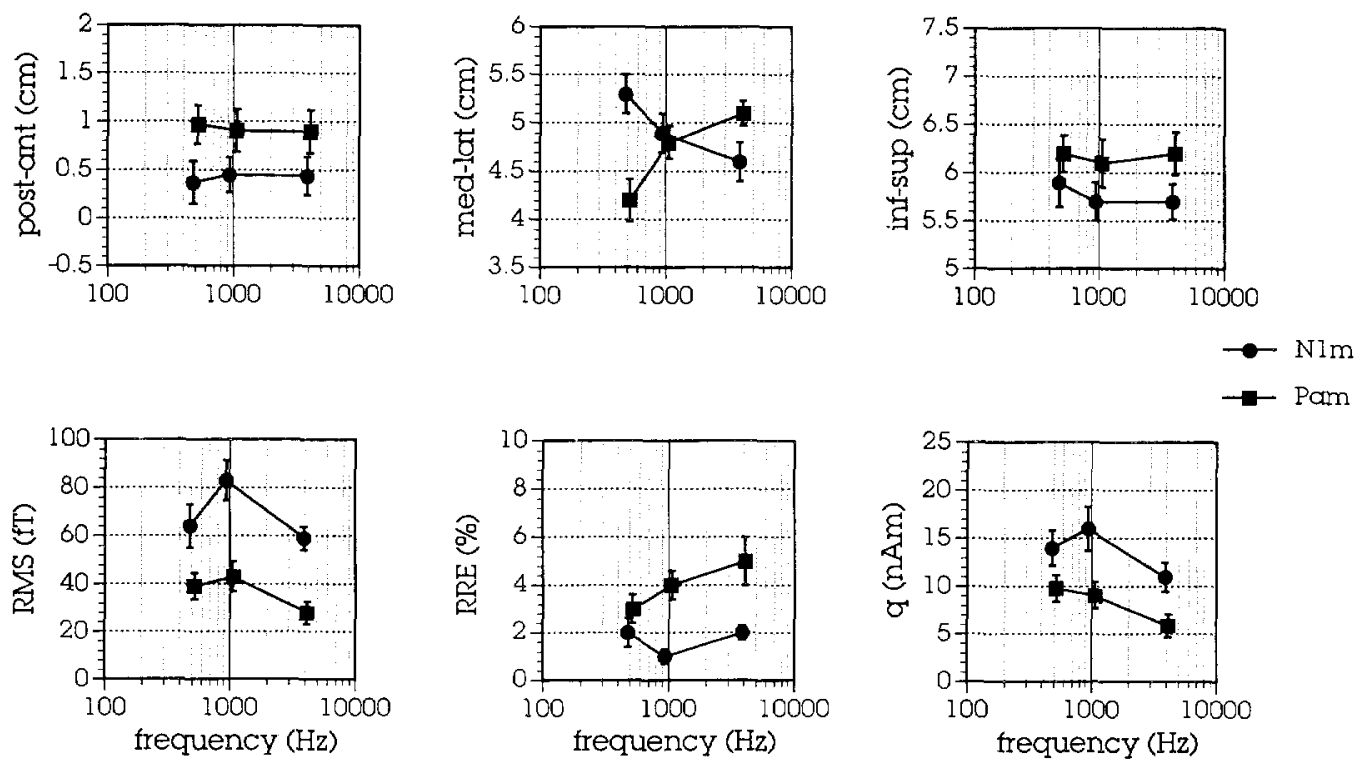

Fig. 5. Dependence of the estimated posterior-anterior, medial-lateral and inferior-superior coordinates of the source locations of Pam (filled squares) and N1m (filled circles), the root mean square and the dipole moment values of the field and the relative residual error of the fit from the stimulus frequency, averaged across the 12 subjects investigated. 
source depth of Pam and N1m evoked by the $4000 \mathrm{~Hz}$ tone differed significantly $(P<0.05)$.

This finding was reproducible in all but one subject (subj. e04) and is shown in Fig. 6. The calculated mediallateral coordinates for $\mathrm{N} 1 \mathrm{~m}$ are indicated by circles, those for Pam by squares. The lines inserted into the scatter plots represent logarithmic fits for the calculated medial-lateral coordinates of $\mathrm{N} 1 \mathrm{~m}$ and Pam. The coefficients of determination (squared correlation coefficients) of these functions are also noted in each scatter plot, indicating that the Pam and $\mathrm{N} 1 \mathrm{~m}$ source locations are linearly increasing and decreasing, respectively, as a function of the logarithm of the stimulus frequency in 10 of 12 subjects (while in the eleventh subject the data do not permit a conclusion). The same tendency to change from more medial to more lateral location with increasing stimulus frequency was found for the source location of the middle latency $\mathrm{P} 1 \mathrm{~m}$ wave, which was discernible for all stimulus frequencies in 3 out of the 12 subjects.

For 4 subjects the Pam and N1m source locations were superimposed onto MRI sections. The overlays of these estimated source locations onto the MR images demonstrate a good correlation of the reconstructed sources with the anatomic structures of the auditory cortex (Talairach and Tournoux, 1988). Fig. 7 presents an example (subj. h04) with axial and coronal views. The Pam and N1m source locations consistently overlap the transverse temporal convolutions as well as the supratemporal plane, which are known to embed the primary and the secondary cortical areas in humans (Brodmann's areas 41, 42, and 22).

Finally, the individual posterior-anterior, medial-lateral and inferior-superior coordinates of the estimated Pam and $\mathrm{N} 1 \mathrm{~m}$ source locations were averaged for each stimulus frequency across subjects. These averaged values are presented in the 3D plot of Fig. 8 and are intended to illustrate the "centers of activity" of tonally corresponding excited neuronal populations generating the Pam and N1m waves. The figure demonstrates spatially separated 3D locations and an obvious mirror-image tonotopic representation of the Pam and N1m source locations with respect to the corresponding frequency of the stimulus. Increasing the frequency Pam source locations move from more medial to more lateral cortical regions, whereas the $\mathrm{N} 1 \mathrm{~m}$ sources move in an opposite direction, from more lateral to more medial regions, but generally to more lateral cortical area. Thus, when projected onto a coronal section (medial-lateral direction) the regions embedding the Pam and N1m sources for the different stimulus frequencies only partly overlap. They differ by less than $5 \mathrm{~mm}$ in anterior-posterior and inferior-superior directions.
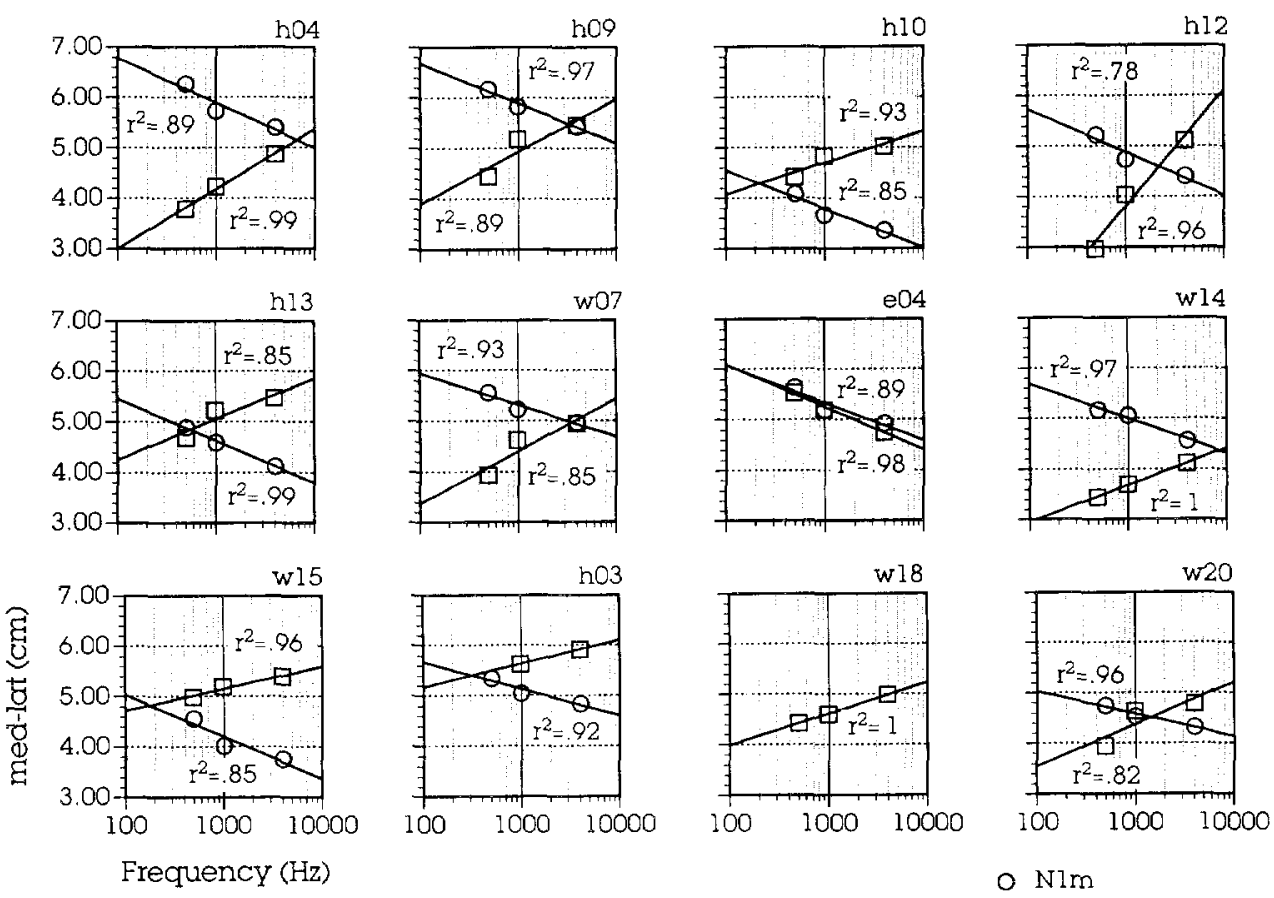

$\square$ Parn

Fig. 6. Dependence of the estimated distance of the source location of the M100 from the origin of the coordinate system of the head frame in medial-lateral direction for each test subject investigated. This value represents indirectly the depth of the corresponding equivalent source and is shown on a semi-logarithmic scale. The abscissa represents the stimulus frequency, and the ordinate the $y$ coordinate of the estimated source location. Although the values on the $y$-axes vary across subjects, the difference between the highest and the lowest value amounts to a constant $3 \mathrm{~cm}$. The thick lines represent logarithmic function fits to the y values. The coefficients of determination (squared correlation coefficients) of these functions are noted in each plot. 


\section{Discussion}

In this first multi-channel coherent MEG/EEG group study of the human auditory cortex, stable auditory evoked middle latency responses (wave $\mathrm{Pam} / \mathrm{Pa}$ ) and slow latency responses (wave $\mathrm{N} 1 \mathrm{~m} / \mathrm{N} 1$ ) were obtained from each of 12 subjects and at 3 stimulus frequencies $(500,1000$ and $4000 \mathrm{~Hz}$ ). The potential and current density topographical brain mapping and the magnetic and electric source analyses produced consistent results: the sources of the major wave $\mathrm{Pa}$ of the middle latency complex were found to be located within the auditory cortex. In line with other observations, this was also true for the sources of the slow auditory evoked responses (N1), which are located about $0.5-1 \mathrm{~cm}$ more posterior than the region occupied by the $\mathrm{Pa}$ sources. Along the medial-lateral axis, the change in location with pitch differed significantly for the two components. Consistent with earlier results, when stimulus frequencies were increased the $\mathrm{N} 1 \mathrm{~m}$ location shifted to deeper structures along the surface of the auditory cortex. The Pam demonstrated a mirrored tonotopy; the higher frequencies were located more laterally than the lower frequencies. The Pa tonotopic map was located anterior to the mirror map of N1. The Pa source organization is in good agreement with the results of animal studies.

The other middle latency waves $\mathrm{Na}, \mathrm{Nb}$ and $\mathrm{P} 1$, although present in some subjects, were not systematically discernible and had very variable scalp topography in MEG as well as in EEG data. It is very likely that this was due to the stimulus paradigm applied in this study. The relatively long stimulus duration of $50 \mathrm{msec}$ with $3 \mathrm{msec}$ rise/decay time and the moderate intensity of $60 \mathrm{~dB} \mathrm{nHL}$ were designed and used to guarantee the best possible frequency specificity of the evoked middle latency responses. However, they probably do not have a strong enough synchronization effect to reliably elicit middle latency waves earlier than Pa (Scherg et al., 1989). The small percentage of responses in which the $P 1$ wave occurred can be understood in terms of the monaural stimulation employed in this study; monaural stimulation is less effective for eliciting the P1 than binaural stimulation (Cacace et al., 1990), especially when a relatively high stimulus repetition rate is used (Erwin and Buchwald, 1986a). The argument that some waves may go undetected

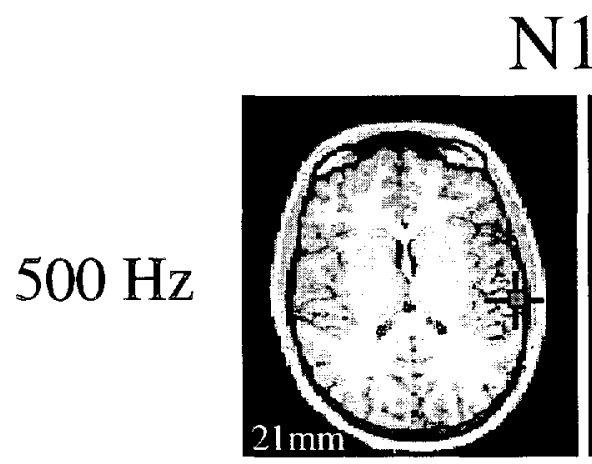

$\mathrm{N} 1 \mathrm{~m}$
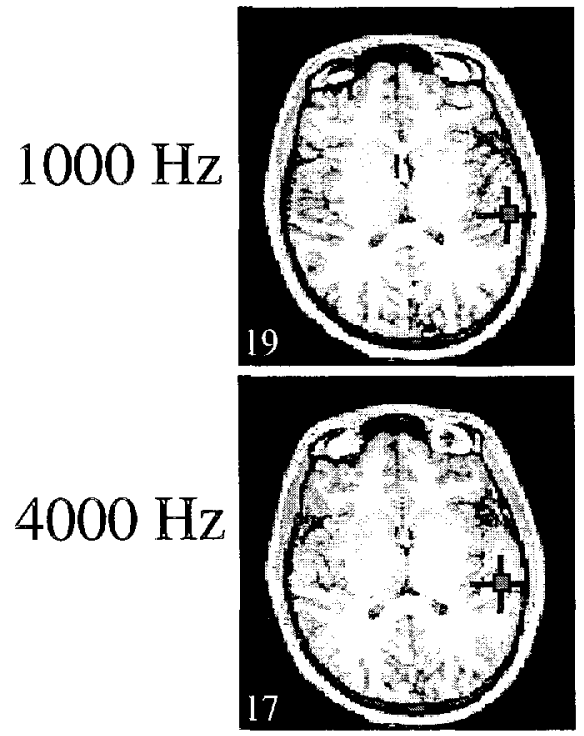
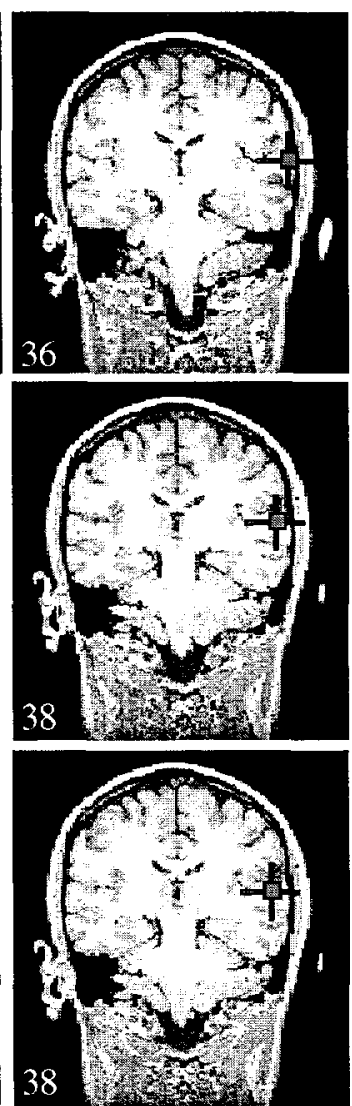

Pam
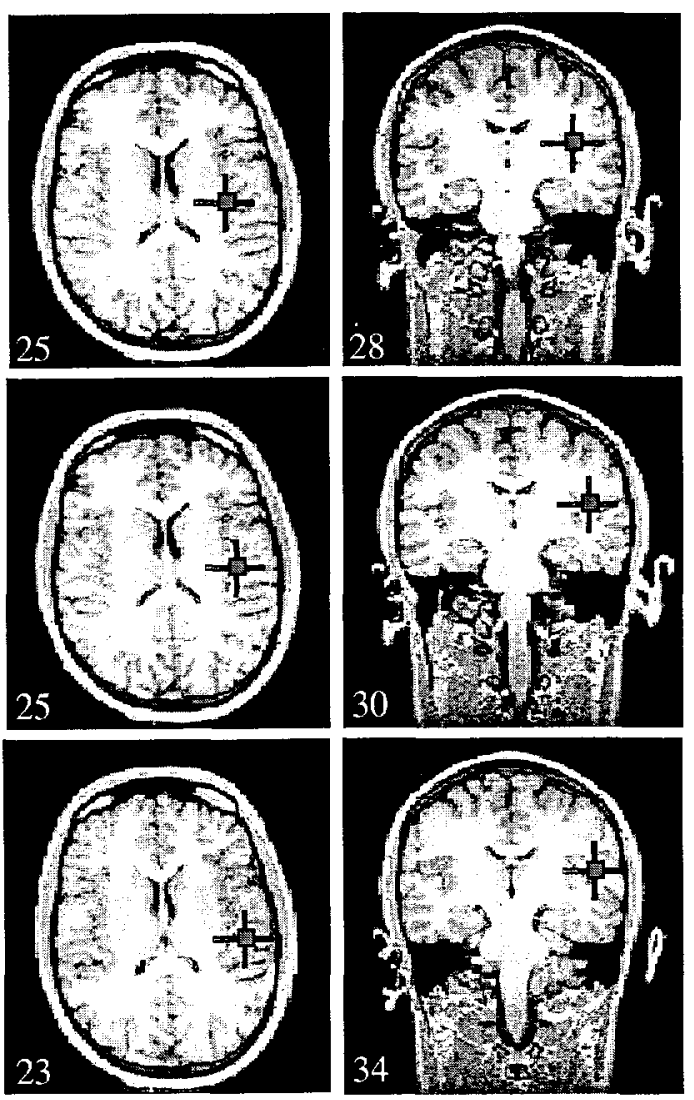

Fig. 7. Superimposition of the estimated Pam and N1m source locations of subject h04 (filled squares) onto the individual axial and coronal MRI slices. The numbers, inserted on the left of each slice, mean the distance from the center of the measuring coil. In the axial slices these values have a negative sign, the axis orientation is from cranial to caudal (positive to caudal). In coronal slices the sign is positive, the axis orientation is from ventral to dorsal (positive to dorsal). 


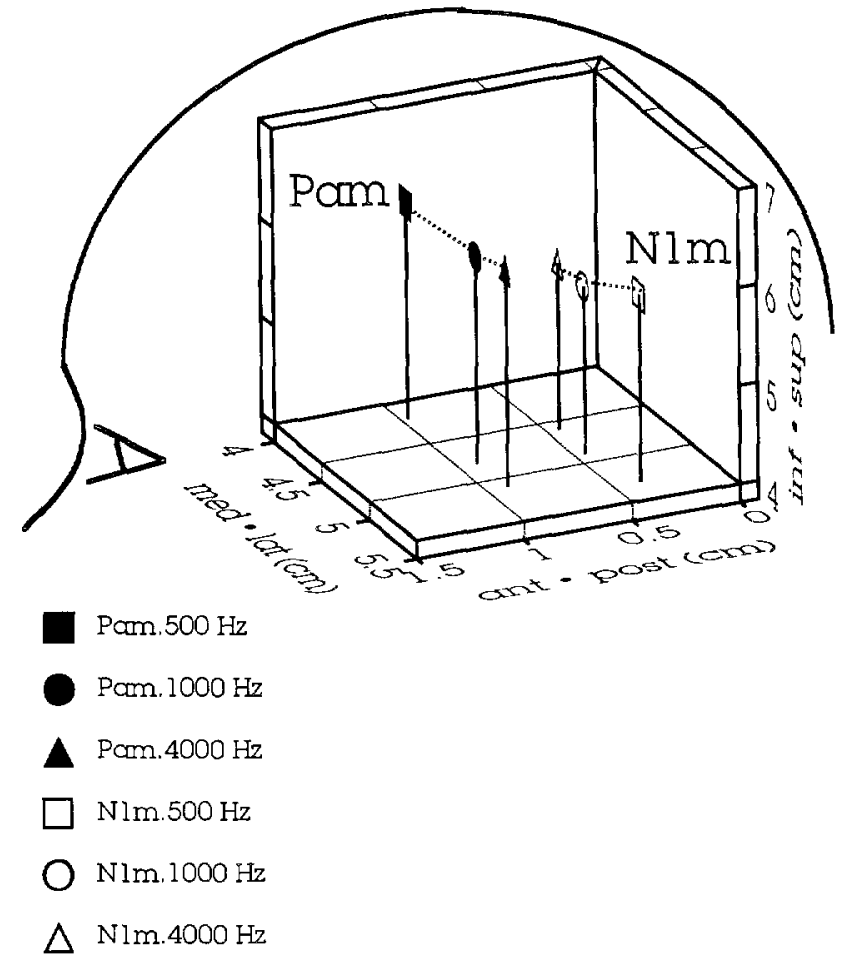

Fig. 8. Mean 3D source locations of Pam and N1m for the 3 different stimulus frequencies averaged across subjects. The coordinate system of these source locations is described in the Methods section.

due to the orientation of their current dipoles seems to be invalid, since the present study employed not only MEG measurements, but also EEG recordings.

Our analysis has thus been focused on the most prominent wave in the middle latency response complex, the $\mathrm{Pa} / \mathrm{Pam}$ and on corresponding findings for the extensively studied N1/N1m wave. Pa showed clear polarity reversal across electrodes approximately delineating the Sylvian fissure (T3, TP3, and P3 in the left and T4, TP4 and P4 in the right hemisphere). This polarity reversal is topographically similar, although not identical, to what was observed for the N1 wave. Mapping the current density exhibited major contributions from generators in the auditory cortex. A similar topography over both hemiscalps suggests that both hemispheres are simultaneously active during the $\mathbf{P a}$ wave. The $\mathrm{Pa}$ topography differed from that of $\mathrm{N} 1$; apart from the difference in polarity, the $\mathrm{Pa}$ scalp potential distribution seemed to be globally tilted toward frontal areas as compared to N1. Similar tilt results were also observed in the magnetic field maps of Pam and $\mathrm{N} 1 \mathrm{~m}$. This suggests that these two waves do not share the same underlying sources. Furthermore, the locations of the sink of the $\mathrm{Pa}$ and the source of $\mathrm{N} 1$ indicated more anterior and inferior locations for the $\mathrm{Pa}$ generators than for the $\mathrm{N} 1$ generators. Moreover, for the $\mathrm{Pa}$ wave, the positive potential and positive source values had larger amplitudes than their negative counterparts. This suggests that the major $\mathrm{Pa}$ generators do not conform to a strict tangentially orientation with respect to the scalp surface.

\subsection{Different locations of $\mathrm{Pa}$ and $N 1$ equivalent sources within the auditory cortex}

Several overlapping sources between 70 and $150 \mathrm{msec}$ have been proposed (see Näätänen and Picton, 1987) to account for N1. The aim of our dipole analysis was not to disclose all different generators active in the auditory cortex, but rather to consider a model which permitted a description of the tonotopic organization in the cortex. Since only waves with a good signal-to-noise ratio served such a purpose, we focused on $\mathrm{Pa}$ and $\mathrm{N} 1$ equivalent sources and employed for analysis relatively short intervals around the $\mathrm{Pa}(25-35 \mathrm{msec})$ and $\mathrm{N} 1(75-100 \mathrm{msec})$ peaks. In these time periods, the neural activity can be fairly well modeled by one dipole in each hemisphere. However, it should be noted that the source modeling, presently employed, allowed us to detect only locations associated with a center of activity. Due to the moderate signal-to-noise ratio in individual EEG recordings, especially for the middle latency responses, dipole modeling based on individual subject data could lead to rather variable dipole solutions and, sometimes, to non-physiological results. Therefore, the EEG dipole modeling was performed on the cross-subject grand average responses. The $\mathrm{Pa}$ and $\mathrm{N} 1$ equivalent sources were found to be located within the area of the auditory cortex. The EEG source analysis indicated that the $\mathrm{Pa}$ source is located about $1 \mathrm{~cm}$ more anterior than the $\mathrm{N} 1$ source.

The results of the MEG source analysis agree with those of the EEG source analysis. The MEG analyses also indicate that the major components of the middle latency and the slow auditory evoked fields, Pam and N1m, respectively (with latency difference of about $60 \mathrm{msec}$ ), represent the activity of distinct neural populations within the auditory cortex, with the Pam neuronal pool being located more anterior than the majority of neurons contributing to $\mathrm{N} 1 \mathrm{~m}$. Pam seems to display the activity of auditory cortical regions located on the transverse gyri of Heschl based on its latency as well as its estimated source locations projected onto the individual MRIs. This result obtained in humans can be correlated with the experimental results of Arezzo et al. (1975), obtained from the auditory cortex of alert rhesus monkeys. The P22 wave (latency of about $22 \mathrm{msec}$ ), representing the activity of the primary auditory cortex of the rhesus monkey can be regarded as analogous to the $\mathrm{Pa}$ in humans. The center of cortical activities contributing to the $\mathrm{N} 1 \mathrm{~m}$ is slightly posterior and lateral to the Pam generators. This MEG source analysis result is in agreement with that of the EEG analysis and indicates that the secondary auditory areas at the supratemporal plane are the generators of N1, a suggestion consistent with previous electric and magnetic studies of the human auditory cortex (Scherg and Von Cramon, 
1985; Hari, 1990; Liegeois-Chauvel et al., 1990; Bertrand et al., 1991; Pantev et al., 1991).

\subsection{Mirror-image tonotopically organized auditory corti- cal areas}

A fundamentally different functional organization of the middle latency $(\mathrm{Pa} / \mathrm{Pam})$ and the slow auditory evoked responses $(\mathrm{N} 1 / \mathrm{N} 1 \mathrm{~m})$ was observed in the electric scalp potential and magnetic field topographies and in the corresponding current density maps. For N1, the frequency effect on topography agrees with previous studies (Bertrand et al., 1991; Woods et al., 1993). In correspondence with the EEG data, a rotation of the magnetic field topography has been observed in the present study and agrees with previous report of Tiitinen et al. (1993). For the Pa wave, similar topographic changes were observed when the stimulus frequency varied. The topographic changes should again be interpreted as a tilt in the orientation of the underlying generators, being both more frontally and more medially oriented for higher frequencies. These findings of a frontal shift in topography are consistent with the findings of larger $\mathrm{Pa}$ amplitude at the vertex for low frequency stimuli (Thornton et al., 1977; Scherg and Volk, 1983; Kraus and McGee, 1988).

These observations were consistent across subjects and were confirmed by the magnetic and electric source analyses. Two tonotopic maps were not only obvious from the source locations, but also from the change in orientation of the $\mathrm{Pa}$ and $\mathrm{N} 1$ sources. The organization along the frequency axis of these maps cannot be derived from the electric source analysis as the uncertainty of the dipole locations is to high. The magnetic source analysis demonstrates, however, two mirror-imaged maps with respect to the frequency representation. These non-invasively obtained results in humans are in agreement with results obtained in animal experiments (Woolsey and Walzl, 1942; Woolsey, 1960, 1971; Merzenich et al., 1973, 1975). Application of microelectrode mapping and neuroanatomical tracing techniques have shown that in cats both the primary auditory cortex (AI) and the anterior auditory field (AAF), which is located rostrally to Al, show complete and highly ordered representations of the cochlea. Moreover, AAF displays a reversal in cochlear place representation across its border in AI, with the most basal portion of the cochlea represented along their mutual boundary.

Galaburda and Sanides (1980) noted that there are 7 secondary areas surrounding the primary auditory cortex. In our study one tonotopically organized cortical area is represented by the sources of the $\mathrm{Pa}$ responses, which might be generated in the primary auditory areas (Brodmann's areas 41 and 42 ). The other tonotopically organized area is represented by the N1 equivalent sources, which receive contributions from secondary auditory areas at the supratemporal plane (Brodmann's area 22). The plausibility of this interpretation is supported by the pro- jections made of the estimated source locations onto the corresponding individual MRIs. In summary, we have demonstrated two tonotopic maps differing in location and mirrored with respect to their frequency dependence.

\section{Acknowledgements}

This work was supported by grants from the Deutsche Forschungsgemeinschaft (Klinische Forschergruppe "Biomagnetismus und Biosignalanalyse') and the European Science Foundation (European Neuroscience Program).

The authors thank Dr. Ed Taub for helpful comments and Bernhard Ross and Marc Thevenet for their assistance in recording and evaluating the data.

\section{References}

Annctt, M. The binomial distribution of right, mixed and left-handed. Quart. J. Exp. Psychol., 1967, 19: 327--333.

Arezzo, A., Pickoff, A. and Vaughan, H.G. The sources and intracerebral distribution of auditory evoked potentials in the alert rhesus monkey. Brain Res., 1975, 90: 57-73.

Bertrand, O., Perrin, F., Echallier, J.F. and Pernier, J. Topography and Model Analysis of Auditory Evoked Potentials: Tonotopic Aspects. Hans Huber, Toronto, 1988: 75-82.

Bertrand, O., Perrin, P. and Pernier, J. Evidence for a tonotopic organisation of the auditory cortex observed with auditory evoked potentials. Acta Otolaryngol. (Stockh.), 1991, Suppl. 491: 116-123.

Bickford, R.G., Jacobson, J.L. and Cody, D.T.R. Nature of average evoked potentials to sound and other stimuli in man. Ann. NY Acad. Sci., 1964, 112: 204-223.

Buchwald, J.S., Hinman, C., Norman, R.I., Huang, C.M. and Brown, K.A. Middle and long latency auditory evoked responses recorded from the vertex of normal and chronically lesioned cats. Brain Res., 1981, 205: 91-109

Cacace, A., Satya-Murti, S. and Wolpaw, J. Human middle latency auditory evoked potentials: vertex and temporal components. Electroenceph. clin. Neurophysiol., 1990, 77: 6-18.

Celesia, G.G. Organization of auditory cortical areas in man. Brain, 1976, 99: $403-414$.

Cohen, M. Coronal topography of the middle latency auditory evoked potentials (MLAEPs) in man. Electrocnceph. clin. Neurophysiol., $1982,53: 231-236$

Deiber, M.P., Ibañez, V., Bastuji, H., Fischer, C. and Maguière, F. Sequential mapping favours the hypothesis of distinct generators for $\mathrm{Na}$ and $\mathrm{Pa}$ middle-latency auditory evoked potentials. Electroenceph. clin. Neurophysiol., 1988, 71: 187-197.

Deiber, M.P., Ibañez, V., Bastuji, H., Fischer, C. and Mauguière, F. Changes of middle latency auditory evoked potentials during natural sleep in humans. Neurology, 1989, 39: 806-813.

Elberling, C., Bak, C., Kofoed, B., Lebech, J. and Saermark, K. Auditory magnetic ficlds. Source localization and "tonotopical organization" in the right hemisphere of the human brain. Scand. Audiol., 1982, 11: $61-65$.

Erwin, R. and Buchwald, J. Midlatency auditory evoked responses: differential recovery cycle characteristics. Electroenceph. clin. Neurophysiol., 1986a, 64: 417-423.

Erwin, R. and Buchwald, J.S. Midlatency auditory evoked responses: differential effect of sleep in the human. Electroenceph. clin. Neurophysiol., 1986b, 65: 383-392. 
Farlan, W.H., Vivion, M.C. and Goldstein, R. Middle components of the AER to tone-pips in normal hearing and hearing impaired subjects. J. Specch Hear. Res., 1977, 20: 781-798.

Galaburda, A. and Sanides, F. Cytoarchitectonic organization of the human auditory cortex. J. Comp. Neurol., 1980, 190: 597-610.

Hari, R. The neuromagnetic method in the study of the human auditory cortex. In: F. Grandori, M. Hoke and G.L. Romani (Eds.), Auditory Evoked Magnetic Fields and Electric Potentials. Karger, Basel, 1990: $222-282$.

Kraus, $\mathrm{N}$. and McGee, T. Color imaging of the human middle latency response. Ear Hear., 1988, 9: 159-167.

Kraus, N., McGee, T., Littman, T. and Nicol, T. Reticular formation influences on primary and non-primary auditory pathways as reflected by the middle latency response. Brain Res., 1992, 587: 186-194

Lauter, J.L., Herschovitch, P., Formby, C. and Raichle, M.E. Tonotopic organization in the human auditory cortex revealed by positron emission tomography. Hear. Res., 1985, 20: 199-205

Lee, Y.S., Lueders, H., Dinner, D.S., Lesser, R.P., Hahn, J. and Klem, G. Recording of auditory evoked potentials in man using chronic subdural electrodes. Brain, 1984, 107: 115-131.

Liegeois-Chauvel, C., Chauvel, P., Marquis, P., Musolino, A. and Bancaud, J. Intracerebral Recordings of the Primary Auditory Evoked Potentials in Man. Raven Press, New York, 1987: 39-49.

Liegeois-Chauvel, C., Musolino, A. and Chauvel, P. Localization of primary auditory area in man. Brain, 1991, 107: 115-131.

Littman, T., Kraus, N., McGee, T. and Nicol, T. Binaural stimulation reveals functional differences between midline and temporal components of the middle latency response in guinea pigs. Electroenceph. clin. Neurophysiol., 1992, 84: 362-372.

McCarthy, G. and Wond, C.C. Scalp distributions of event related potentials: an ambiguity associated with analysis of variance models. Electroenceph. clin. Neurophysiol., 1985, 62: 203-208.

Mendel, M.I. and Goldstein, R. Early components of the averaged electroencephalic response to constant clicks during all-night sleep. J. Speech Hear. Res., 1971, 14: 829-840.

Merzenich, M.M. and Brugge, J.F. Representation of the cochlear position on the superior temporal plane of the macaque monkey. Brain Res., 1973, 50: 275-296.

Merzenich, M.M., Knight, P.L. and Roth, G.L. Cochleotopic organization of primary auditory cortex in the cat. Brain Res., 1973, 63: 343-346.

Merzenich, M.M., Knight, P.L. and Roth, G.L. Representation of cochlea within primary auditory cortex in cat. J. Neurophysiol., 1975, 38: 231-249.

Merzenich, M.M., Kaas, J.H. and Roth, G.L. Comparison of tonotopic maps in animals. J. Comp. Neurol., 1976, 166: 387-402.

Näätänen, R. and Picton, T. The N1 wave of the electric and magnetic response to sound: a review and an analysis of the component structure. Psychophysiology, 1987, 24: 375-425.

Özdamar, $\ddot{O}$. and Kraus, N. Auditory middle latency responses in humans. Audiology, 1983, 22: 34-49.

Pantev, C., Hoke, M., Lehnertz, K., Lïtkenhöner, B., Anogianakis, G. and Wittkowski, W. Tonotopic organization of the human auditory cortex revealed by transient auditory evoked magnetic fields. Electroenceph. clin. Neurophysiol., 1988, 69: 160-170.

Pantev, C., Hoke, M., Lehnertz, K., Lütkenhöner, B., Fahrendorf, G. and Stöber, U. Identification of sources of brain neuronal activity with high spatiotemporal resolution through combination of neuromagnetic source localization (NMSL) and magnetic resonance imaging (MR1). Electroenceph. clin. Neurophysiol., 1990, 75: 173-184.

Pantev, C., Gallen, C., Hampson, S., Buchanan, S. and Sobel, D. Reproducibility and validity of neuromagnetic source localization using a large array biomagnetometer. Am. J. EEG Technol., 1991, 31: 83-101.

Pantev, C., Elbert, T., Makeig, S., Hampson, S., Eulitz, C. and Hoke, M. Relationship of transient and steady-state auditory evoked fields. Electroenceph. clin. Neurophysiol., 1993, 88: 389-396.

Pelizzone, M., Hari, R., Mäkelä, J.P., Huttunen, J., Ahlfors, S. and
Hämäläinen, M. Cortical origin of middle latency auditory evoked responses in man. Neurosci. Lett., 1987, 82: 303-307.

Pernier, J., Pcrrin, F. and Bertrand, O. Scalp current density fields: concepts and properties. Electroenceph. clin. Neurophysiol., 1988, 69: $385-389$.

Perrin, F., Pernier, J., Bertrand, O. and Echallier, J.F. Spherical splines for scalp potential and current density mapping. Electroenceph. clin. Neurophysiol., 1989, 72: 184-187.

Perrin, F., Bertrand, O., Giard, M.H. and Pernier, J. Precautions in topographic mapping and in evoked potential map rcading. J. Clin. Neurophysiol., 1990, 7: 498-506.

Picton, T.W., Hillyard, S.A., Krausz, H.I. and Galambos, R. Human auditory cvoked potentials. I. Evaluation of components. Electroenceph. clin. Neurophysiol., 1974, 36: 179-190.

Recanzone, G.H., Schreiner, C.E. and Merzenich, M.M. Plasticity in the frequency representation of primary auditory cortex following discrimination training in adult owl monkeys. J. Neurosci., 1993, 13: $87-103$.

Reite, M., Teale, P.. Zimmerman, J., Davis, K. and Whalen, J. Source location of a $50 \mathrm{msec}$ latency auditory evoked field component. Electroenceph. clin. Neurophysiol., 1988, 70: 490-498.

Romani, G.L., Williamson, S.J. and Kaufman, L. Tonotopic organization of the human auditory cortcx. Science, 1982, 216: 1339-1340.

Rush, S. and Driscoll, D.A. EEG electrode scnsitivity. An application of reciprocity. IEEE Trans. Biomed. Eng., 1969, 16: 15-22.

Sarvas, J. Basic mathematical and electromagnetic concepts of the biomagnetic inverse problem. Phys. Med. Biol., 1987, 32: 11-22.

Scherg, M. Fundamentals of dipole source potential analysis. In: $F$. Grandori, M. Hoke and G.L. Romani (Eds.), Auditory Evoked Magnetic Fields and Electric Potentials. Karger, Basel, 1990: 40-69.

Scherg, M. and Volk, S.A. Frequency specificity of simultaneously recorded early and middle latency auditory evoked potentials. Electroenceph. clin. Neurophysiol., 1983, 56: 443-452.

Scherg, M. and Von Cramon, D. Two bilateral sources of the late AEP as identified by a spatio-temporal model. Electroenceph. clin. Neurophysiol, 1985, 62: 32-44.

Scherg, M. and Von Cramon, D. Evoked dipole source potentials of the human auditory cortex. Electroenceph. clin. Neurophysiol., 1986, 65: 344-360.

Scherg, M. and Von Cramon, D. Dipole source potentials of the auditory cortex in normal subjects and in patients with temporal lobe lesions. In: F. Grandori, M. Hoke and G.L. Romani (Eds.), Auditory Evoked Magnetic Fields and Electric Potentials. Karger, Basel, 1990: 165-193.

Scherg, M., Hari, R. and Hämäläinen, M. Frequency Specific Sources of the Auditory N19-P30-P50 Response Detected by a Multiple Source Analysis of Evoked Magnetic Fields and Potentials. Plenum Press, New York, 1989: 97-100.

Schreiner, C.E. Functional topographies in the primary auditory cortex of the cat. Acta Otolaryngol. (Stockh.), 1991, Suppl. 491: 7-16.

Steinschneider, M., Tenke, C.E., Schroeder, C.E., Javitt, D.C., Simpson, G.V., Arezzo, J.C. and Vaughan, H.G. Cellular generators of the cortical auditory evoked potential initial component. Electroenceph. clin. Neurophysiol., 1992, 84: 196-200.

Stok, C.J., Meijs, J.W.H. and Peters, M.J. Inverse solutions based on MEG and EEG applied to volume conductor analysis. Phys. Med. Biol., 1987, 32: 99-104.

Streletz, L.J., Katz, L., Hohenberger, M. and Cracco, R.Q. Scalp recorder auditory evoked potentials and sonomotor responses: an evaluation of components and recording techniques. Electroenceph. clin. Neurophysiol., 1977, 43: 192-206.

Talairach, J. and Tournoux, P. Co-Planar Stereotaxic Atlas of the Human Brain. Georg Thieme Verlag, Stuttgart, 1988.

Thornton, A.R., Mendel, M.I. and Anderson, C.V. Effects of stimulus frequency and intensity on middle latency components of the averaged auditory electroencephalographic response. J. Speech Hear. Res., 1977, 20: 81-94

Tiitinen, H., Alho, K., Huotilainen, R., Ilmoniemi, R.J., Simola, J. and 
Näätänen, R. Tonotopic auditory cortex and the magnetoencephalographic (MEG) equivalent of the mismatch negativity. Psychophysiology, 1993, 30: 537-540.

Wood, C.C. and Wolpaw, J.R. Scalp distribution of human auditory evoked potentials. II. Evidence for overlapping sources and involvement of auditory cortex. Electroenceph. clin. Neurophysiol., 1982, 54: 25-38.

Woods, D.L., Kimmo, A. and Algazi, A. Intermodal selective attention: evidence for processing in tonotopic auditory fields. Psychophysiology, 1993, 30: 287-295.
Woolsey, C.N. Organization of the Cortical Auditory System: a Review and Synthesis. Charles C. Thomas, Springfield, IL, 1960: 271-282.

Woolsey, C.N. Tonotopic Organization of the Auditory Cortex. National Consultants, Baltimore, MD, 1971: 271-282.

Woolsey, C.N. and Walzl, E.M. Topical projection of nerve fibers from local regions of the cochlea to the cerebral cortex of the cat. Bull. Johns Hopk. Hosp., 1942, 71: 315-344.

Yamamoto, T., Williamson, S.J., Kaufman, L., Nicholson, C. and Llinás, R. Magnetic localization of neural activity in the human brain. Proc. Nat. Acad. Sci. (USA), 1988, 85: 8732-8736. 